\title{
Efficacy and Safety Data of Osimertinib in Elderly Patients with NSCLC Who Harbor the EGFR T790M Mutation After Failure of Initial EGFR-TKI Treatment
}

\author{
HIROMI FURUTA ${ }^{1}$, TAKEHIRO UEMURA ${ }^{1}$, TATSUYA YOSHIDA ${ }^{1}$, MAKIKO KOBARA ${ }^{2}$, \\ TEPPEI YAMAGUCHI ${ }^{1}$, NAOHIRO WATANABE ${ }^{1}$, JUNICHI SHIMIZU ${ }^{1}$, YOSHITSUGU HORIO ${ }^{1}$, \\ HIROAKI KURODA ${ }^{3}$, YUKINORI SAKAO ${ }^{3}$, YASUSHI YATABE ${ }^{4}$ and TOYOAKI HIDA ${ }^{1}$ \\ ${ }^{1}$ Department of Thoracic Oncology, ${ }^{2}$ Department of Nursing, ${ }^{3}$ Department of Thoracic Surgery and \\ ${ }^{4}$ Department of Pathology and Molecular Diagnostics, Aichi Cancer Center Hospital, Nagoya, Japan
}

\begin{abstract}
Background/Aim: The aim of this study was to evaluate the safety and efficacy of osimertinib for elderly patients, since the data remain limited. Patients and Methods: A total of 77 patients with advanced non-small cell lung cancer (NSCLC) harboring the epidermal growth factor receptor (EGFR) T790M mutation and treated with osimertinib were reviewed. Efficacy and safety indicators, such as EGFR-tyrosine kinase inhibitor (TKI)-related adverse events (AEs) and osimertinib-associated hematotoxicity, were evaluated in elderly patients (elderly group, EG; age, $\geq 75$ years) by comparing them with younger patients (non-EG; aged $<75$ years). The frequency of AEs associated with osimertinib was compared with the initial EGFR-TKI treatment before osimertinib administration in the same patient cohort. Results: Of the total 77 patients, 18 (23\%) were assigned to the EG, whereas 59 (77\%) were assigned to the non-EG. There were no significant differences in overall response rate and progression-free survival between the two groups. Regarding the safety of osimertinib, the EG had significantly more grade $\geq 2$ paronychia than the non-EG (16.6\% vs. 1.6\%, p=0.04). Additionally, the maximum grade of EGFR-TKI-related AEs associated with osimertinib in the EG was significantly lower than that of the initial EGFR-TKI treatment ( $p=0.03)$. Conclusion: Osimertinib is a safe and effective treatment option for elderly patients with advanced NSCLC who harbor the EGFR mutation.
\end{abstract}

Correspondence to: Tatsuya Yoshida, MD, Ph.D., Department of Thoracic Oncology, Aichi Cancer Center Hospital, 1-1 Kanokoden, Chikusa-ku, Nagoya, Aichi 464-8681, Japan. Tel: +81 527626111, Fax: +81 527642963, e-mail: t.yoshida@aichi-cc.jp

Key Words: Osimertinib, EGFR-TKIs-related adverse events, hematotoxicity, NSCLC.
Epidermal growth factor receptor (EGFR) tyrosine kinase inhibitors (TKIs) for advanced EGFR-mutant non-small cell lung cancer (NSCLC) have an overall response rate (ORR) of approximately 60-70\% (1-3). However, almost all patients ultimately developed disease progression after EGFR-TKIs administration. The EGFR T790M pointmutation in exon 20 (T790M), which is an EGFR secondary mutation, has been reported in approximately $50 \%$ of tumors at the time of treatment failure with EGFRTKIs $(4,5)$. The third-generation EGFR-TKI "osimertinib," which is an irreversible mutant-selective EGFR-TKI, is potent and effective against $E G F R$ mutations, including the T790M mutation $(6,7)$.

The randomized phase III AURA3 trial assessed the efficacy and safety of osimertinib as a second-line treatment in patients with EGFR T790M-positive advanced NSCLC, which progressed following first-line EGFR-TKI therapy. That study demonstrated that compared with the standard platinum-doublet chemotherapy, osimertinib led to significant and meaningful improvements in both progression-free survival (PFS) and ORR (8). Moreover, the pivotal randomized phase III FLAURA trial, which compared osimertinib with standard EGFR-TKIs in patients with previously untreated $E G F R$ mutation-positive advanced NSCLC, indicated that patients treated with osimertinib had a significantly longer PFS than those treated with the standard first-generation EGFR-TKIs gefitinib and erlotinib (9).

Two-thirds of all new lung cancer cases are diagnosed in patients aged $>65$ years, and this rate is anticipated to increase owing to the growth of the aging population (10, 11). Treatment strategies in elderly patients with lung cancer have received increasing attention. In general, more adverse events (AEs) of first- and second-generation EGFR-TKIs reportedly occur in elderly patients (age, $\geq 75$ years) than in younger patients $(12,13)$. The FLAURA trial included 
Table I. Patient characteristics ( $N=77)$.

\begin{tabular}{|c|c|c|c|c|}
\hline & All & $\begin{array}{c}\text { Non-Elderly group } \\
\text { (non-EG, }<75 \text { years) } \\
\mathrm{N}=59\end{array}$ & $\begin{array}{c}\text { Elderly group } \\
\text { (EG, } \geq 75 \text { years) } \\
\mathrm{N}=18\end{array}$ & $p$-Value \\
\hline Age, median (Range) & $66(36-86)$ & $62(36-74)$ & $80(75-86)$ & \\
\hline Gender, Female/Male & $53 / 24$ & $39 / 20$ & $14 / 4$ & 0.40 \\
\hline Performance status, $0 / 1 / 2$ & $44 / 30 / 3$ & $33 / 23 / 3$ & $11 / 7 / 0$ & 0.71 \\
\hline$E G F R$ mutation status & & & & \\
\hline $\begin{array}{l}19 \mathrm{del} / \mathrm{L} 858 \mathrm{R} / \text { others } \\
\text { Histology }\end{array}$ & $44 / 32 / 1$ & $35 / 23 / 1$ & $9 / 9 / 0$ & 0.71 \\
\hline $\begin{array}{l}\text { Adenocarcinoma/others } \\
\text { Smoking History }\end{array}$ & $75 / 2$ & $58 / 1$ & $17 / 1$ & 0.42 \\
\hline $\begin{array}{l}\text { Yes/No } \\
\text { Stage at diagnosis }\end{array}$ & $17 / 60$ & $14 / 45$ & $3 / 15$ & 0.75 \\
\hline $\begin{array}{l}\text { Postoperative Recurrence/IIIA/IIIB/IV } \\
\text { Initial EGFR-TKI }\end{array}$ & $25 / 1 / 4 / 47$ & $16 / 1 / 2 / 40$ & $9 / 0 / 2 / 7$ & 0.08 \\
\hline Gefitinib/Erlotinib/Afatinib & $52 / 19 / 6$ & $38 / 16 / 5$ & $14 / 3 / 1$ & 0.50 \\
\hline
\end{tabular}

EGFR-TKI: Epidermal growth factor receptor tyrosine kinase inhibitor.

patients of all ages and demonstrated that the safety profile of osimertinib was similar to that of gefitinib and erlotinib (9). Additionally, the frequency of serious AEs was lower in patients treated with osimertinib than in those treated with first-generation EGFR-TKIs. This indicates that osimertinib treatment could be more feasible for elderly patients. However, these data are not sufficient to completely assess the safety and efficacy of osimertinib in elderly patients.

Here, the efficacy and safety of osimertinib was compared between elderly and younger patients. The frequency of AEs associated with osimertinib treatment was also compared with that associated with initial EGFR-TKI treatment before osimertinib treatment in the same patients.

\section{Patients and Methods}

Patients. Between July 2014 and June 2017, we reviewed the records of 77 patients with advanced NSCLC at our institute who harbored the T790M mutation and were treated with osimertinib after treatment failure with first- and second-generation EGFR-TKIs (gefitinib, erlotinib, or afatinib). T790M status was confirmed using plasma samples (Roche cobas ${ }^{\circledR} E G F R$ mutation test v2) or tissue samples as previously reported $(14,15)$. We also evaluated patient characteristics, initial EGFR-TKI- and osimertinib-associated AEs, and clinical outcomes of osimertinib treatment. To evaluate the efficacy and safety of osimertinib in the elderly, the patients were divided into two groups: an elderly group (age, $\geq 75$ years; EG) and a non-elderly group (age, $<75$ years; non-EG). The objective tumor response to osimertinib was radiographically assessed using the response evaluation criteria in solid tumors (RECIST; version 1.1) (16). The ORR was calculated as the total percentage of patients with a complete response or a partial response. AEs were assessed according to the Common Terminology Criteria for Adverse Events (CTCAE; version 4.0). In this study, rash, diarrhea, paronychia, stomatitis, and elevation of aspartate aminotransferase (AST)/alanine aminotransferase (ALT) were considered EGFR-TKI-related AEs. This retrospective study was approved by the Institutional Review Board of the Aichi Cancer Center, Japan.

Statistical analysis. All statistical analyses were performed using the Graph Pad Prism version 7 for Windows (Graphpad Software Inc., San Diego, CA, USA) or JMP version 9 for Windows statistical software packages (SAS Institute, Cary, NC, USA). Differences in categorical outcomes were evaluated using the $\chi^{2}$ or the Fisher's exact tests, as appropriate. Changes in the maximum grade of AEs between the initial EGFR-TKI treatment and osimertinib treatment were analyzed using paired $t$-test. PFS was measured from the start of osimertinib administration until the date of RECIST-progression disease. Overall survival (OS) was measured from the start of osimertinib administration to death and was censored at the date of the last visit for patients whose death could not be confirmed. Survival probabilities were estimated using the Kaplan-Meier method wherein differences in the variables were calculated using the logrank test. All $p$-values were two-sided, and $p<0.05$ was considered statistically significant, unless otherwise stated.

\section{Results}

Patient characteristics. Patient characteristics are listed in Table I. The median age of all the patients was 66 years (range $=36-$ 86 years). Of the total 77 patients, $59(77 \%)$ were aged $<75$ years, whereas $18(23 \%)$ were aged $\geq 75$ years. No differences were observed between the two groups regarding patient characteristics (including PS, EGFR mutation status, histology stage at diagnosis, and smoking history). As EGFR-TKIs, gefitinib, erlotinib, and afatinib were administered to 38, 16, and 5 non-EG patients and 14,3, and 1 EG patients, respectively.

Efficacy and safety of osimertinib. The ORR was $50.8 \%$ in the non-EG patients and $61.1 \%$ in the EG patients $(p=0.59$; Table 


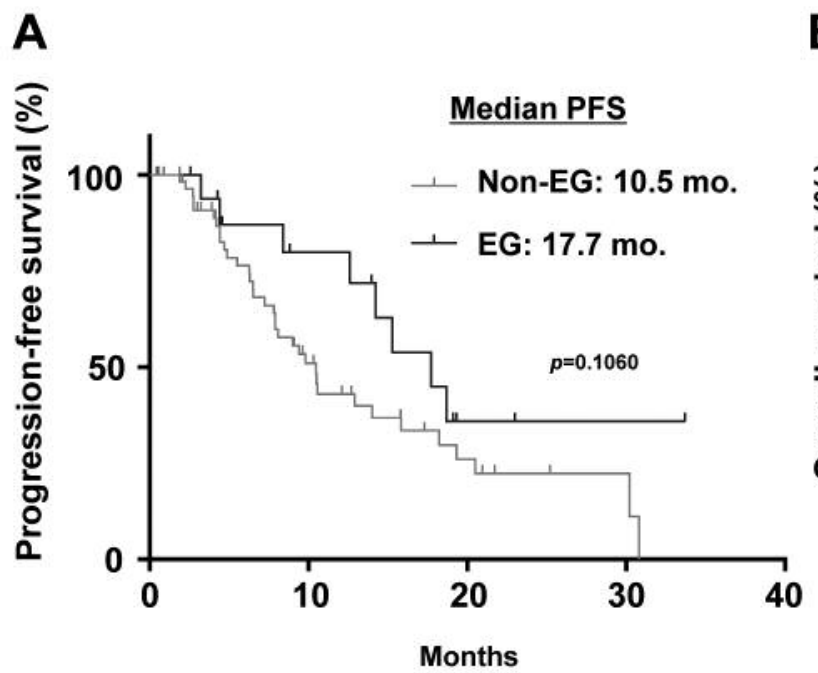

B

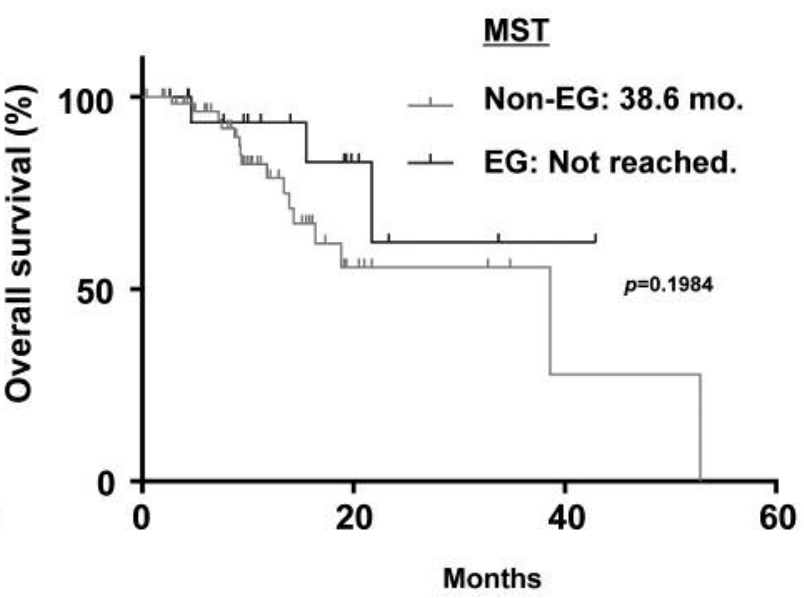

Figure 1. Progression-free survival $(A)$ and overall survival $(B)$ in elderly patients $(E G ; N=18)$ and non-EG patients $(N=59)$.

II). The median PFS was 10.5 months $(95 \% \mathrm{CI}=7.8-15.8)$ in the non-EG patients and 17.7 months in the EG patients $(95 \% \mathrm{CI}=8.4-$ not reached $[\mathrm{NR}])(\mathrm{p}=0.11$; Figure 1A). Although PFS associated with the EG was longer, there were no significant differences between the EG and non-EG. Additionally, there were no significant differences in OS $(\mathrm{EG}=38.6$ months; 95\%CI=14.3-52.8 vs. non-EG, NR; $95 \% \mathrm{CI}=15.5-\mathrm{NR})(p=0.20$; Figure 1B). The frequencies of EGFR-TKI-related AEs and the hematotoxicity associated with osimertinib in the EG and non-EG patients are presented in Figure 2. In both groups, thrombocytopenia was the most common $\mathrm{AE}$ associated with osimertinib. There were no significant differences in the frequency of all-grades of EGFRTKI-related AEs and the hematotoxicity between the EG and non-EG, although the frequency of hematotoxicity was higher in the EG. However, the EG had significantly more instances of grade $\geq 2$ paronychia ( $16.6 \% v s .1 .6 \%, p=0.04$ ). In contrast, there were no significant differences in the frequencies of dose reduction or treatment discontinuation between the EG and non-EG (Table III). Among the 7 EG patients who underwent dose reduction from $80 \mathrm{mg}$ to $40 \mathrm{mg}, 1$ had elevated creatinine levels (grade 2), 1 had fatigue (grade 2), 2 had paronychia (grade 2), 1 had stomatitis (grade 2) and 2 had appetite loss (grade 1). One patient in each group discontinued treatment owing to interstitial lung disease.

Inter-comparison of EGFR-TKI-related AEs between initial EGFR-TKI treatment and osimertinib in EG. To evaluate the differences in AEs between the initial EGFR-TKI and osimertinib treatments, the frequency of EGFR-TKI-specific AEs and hematotoxicity associated with osimertinib were compared to those of initial EGFR-TKI treatments before
Table II. Overall Response to osimertinib (N=77).

\begin{tabular}{lccc}
\hline Response & $\begin{array}{c}\text { Non-EG } \\
(\mathrm{N}=59)\end{array}$ & $\begin{array}{c}\text { EG } \\
(\mathrm{N}=18)\end{array}$ & $p$-Value \\
\hline Partial response & 30 & 11 & \\
Stable disease & 14 & 4 & \\
Progressive disease & 8 & 2 & \\
Not evaluable & 7 & 1 & \\
Overall response rate & $50.8 \%$ & $61.1 \%$ & 0.59 \\
\hline
\end{tabular}

osimertinib therapy in the same patients. The maximum grade of EGFR-TKI-related AEs associated with osimertinib was significantly lower than that associated with initial EGFR-TKI treatment ( $p=0.03$, Figure 3A), although two patients had higher-grade EGFR-TKI-related AEs associated with osimertinib than their AEs after initial EGFR-TKI treatment. In contrast, the maximum grade of hematotoxicity in patients treated with osimertinib was significantly higher than of patients treated with initial EGFR-TKI treatment $(p<0.01$, Figure 3B); however, not all hematotoxicities led to dose modification.

\section{Discussion}

Our study indicated no significant differences in the frequency of dose reduction or treatment discontinuation between EG and non-EG, although the EG demonstrated a significantly higher frequency of grade $\geq 2$ severity paronychia than the non-EG. Additionally, the maximum grade of the EGFR-TKI-related AEs associated with 

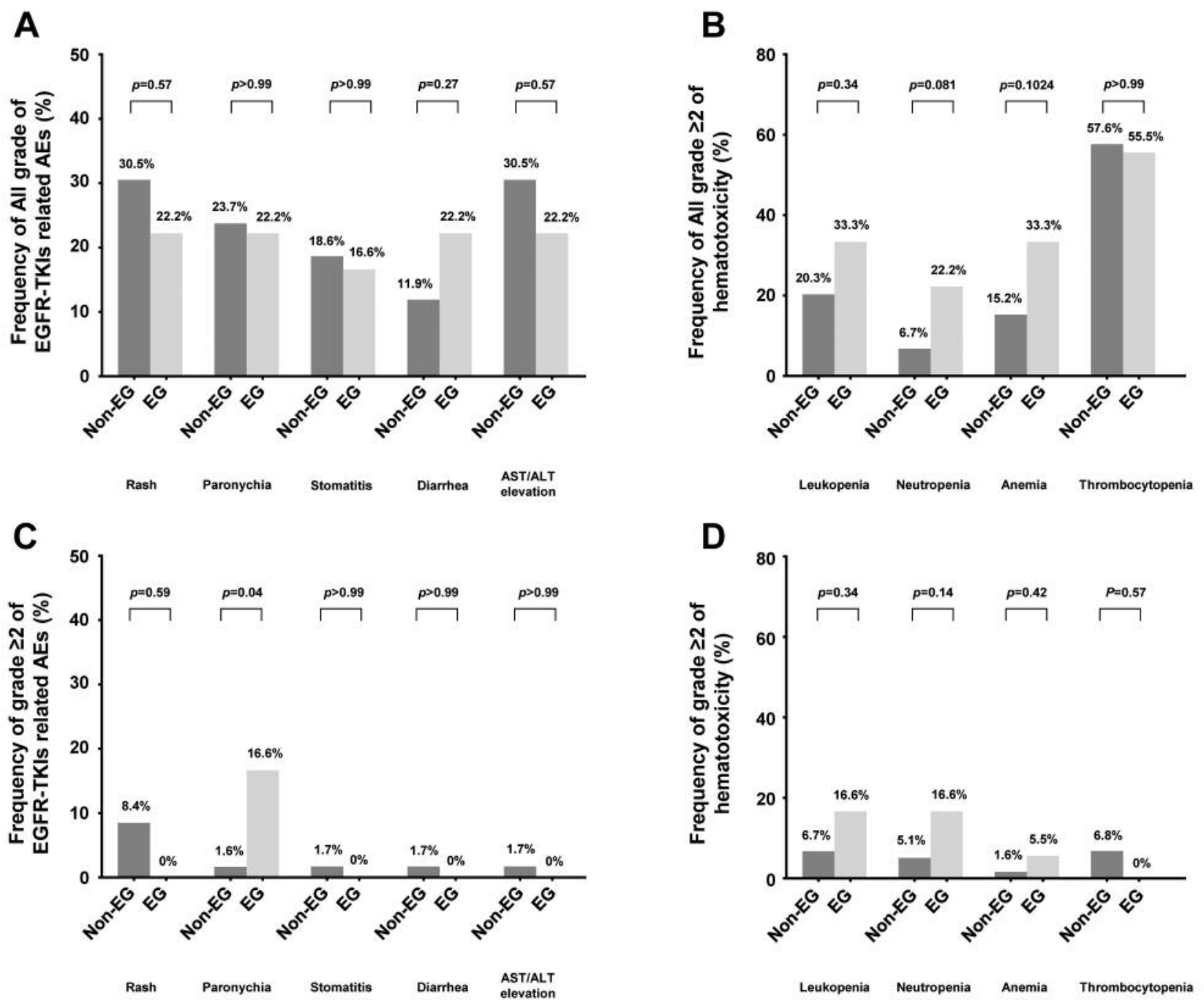

Figure 2. Frequency of all-grade and Grade $\geq 2$ EGFR-TKI-related AEs ( $A$ and $C$ ) and hematotoxicity $(B$ and $D)$ of osimertinib in the elderly patients $(E G ; N=18)$ and non-EG patients $(N=59)$.

osimertinib in EG was significantly lower than that associated with initial EGFR-TKI treatment $(p=0.03)$. However, the maximum grade of hematotoxicity in patients treated with osimertinib (not leading to dose modification) was significantly higher than in those treated with initial EGFR-TKI treatment $(p<0.01)$. Therefore, osimertinib may be a more feasible treatment option in elderly patients with EGFR-positive NSCLC.

Elderly patients generally have more comorbidities and a more compromised organ function than younger patients. Some studies have evaluated the efficacy and feasibility of first-line EGFR-TKIs, such as gefitinib and erlotinib, in elderly patients with NSCLC who harbor an EGFR mutation $(12,17,18)$. These studies reported that EGFR-TKIs were highly effective with acceptable toxicity incidence in elderly patients with advanced NSCLC who harbored EGFR mutations. Conversely, Rossi et al. reported that elderly patients (age, $>70$ years) experienced more toxicities and were more likely to have grade $\geq 3$ rash, fatigue, and diarrhea (19). A greater number of elderly than younger patients require discontinuation or reduction of their EGFR-TKI dosage. Recently, Tanaka et al. conducted a phase I study of afatinib in patients aged $\geq 75$ years with advanced NSCLC who harbored EGFR mutations; they reported that the recommended dose for elderly patients was $30 \mathrm{mg} /$ day, which is $10 \mathrm{mg}$ less than the starting dose of afatinib in younger patients (20).

In contrast, the FLAURA trial demonstrated that the safety profile of osimertinib was similar to that of gefitinib and erlotinib (9). Additionally, the frequency of serious 
A

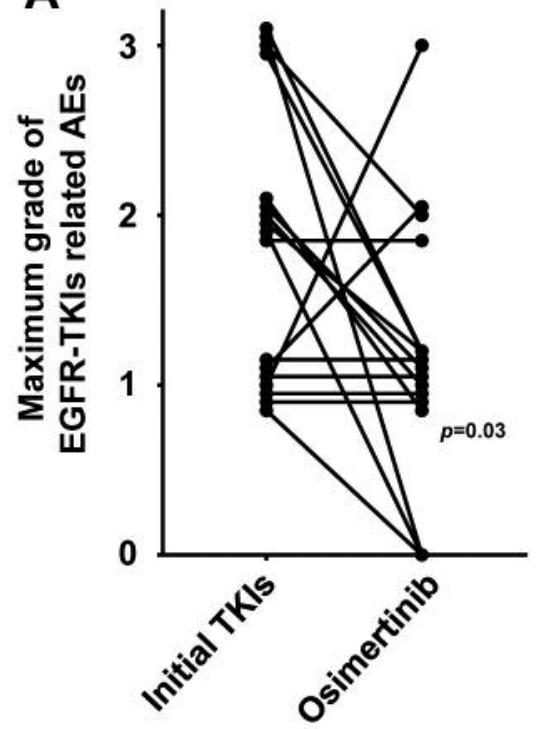

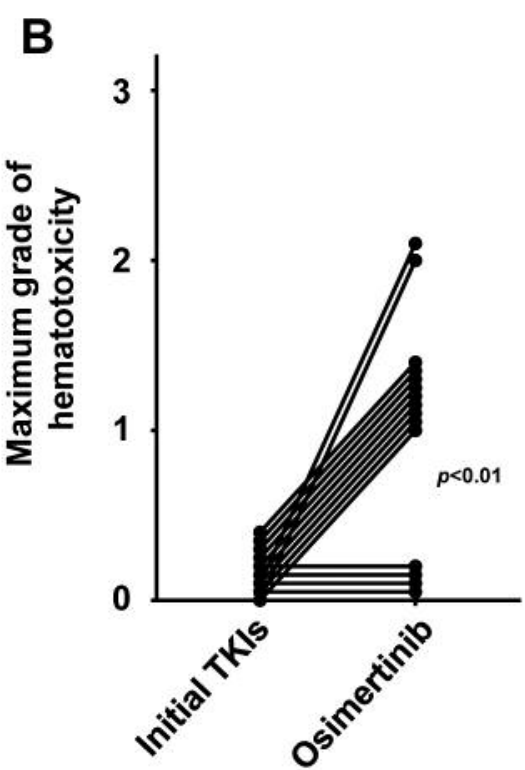

Figure 3. Inter-comparison of maximum grade of EGFR-TKI-related AEs (A) and hematotoxicity (B) between initial EGFR-TKIs and osimertinib in elderly patients $(E G)$.

Table III. Details of dose reduction and discontinuation.

\begin{tabular}{|c|c|c|c|}
\hline & Non-EG (N=59) & $\mathrm{EG}(\mathrm{N}=18)$ & $p$-Value \\
\hline Dose reduction & $\begin{array}{c}\mathrm{N}=10 \\
\text { Bradycardia }(\text { grade } 2 ; \mathrm{N}=1) \\
\text { Paronychia }(\text { grade } 2 ; \mathrm{N}=1) \\
\text { Stomatitis }(\text { grade } 2 ; \mathrm{N}=2) \\
\text { AST/ALT elevation }(\text { grade } 2 / 3 ; \mathrm{N}=1 / 1) \\
\text { Fatigue }(\text { grade } 2 ; \mathrm{N}=1) \\
\text { DVT }(\text { grade } 2 ; \mathrm{N}=1) \\
\text { Diarrhea }(\text { grade } 2 / 3 ; \mathrm{N}=1 / 1)\end{array}$ & $\begin{array}{l}\mathrm{N}=7 \\
\text { Appetite loss (grade } 1 ; \mathrm{N}=2) \\
\text { Stomatitis (grade } 2 ; \mathrm{N}=1 \text { ) } \\
\text { Paronychia (grade } 2 ; \mathrm{N}=2 \text { ) } \\
\text { Cre elevation (grade } 2 ; \mathrm{N}=1 \text { ) } \\
\text { Fatigue (grade } 2 ; \mathrm{N}=1 \text { ) }\end{array}$ & 0.18 \\
\hline Treatment Discontinuation & $\begin{array}{c}\mathrm{N}=1 \\
\text { ILD }(\text { grade } 1 ; \mathrm{N}=1)\end{array}$ & $\begin{array}{c}\mathrm{N}=1 \\
\text { ILD }(\text { grade } 3 ; \mathrm{N}=1)\end{array}$ & 0.43 \\
\hline
\end{tabular}

AST: Aspartate aminotransferase; ALT: alanine aminotransferase; ILD: interstitial lung disease; DVT: deep vein thrombosis; Cre: creatinine.

AEs was lower in patients treated with osimertinib than in those treated with first-generation EGFR-TKIs. This indicates that osimertinib treatment could be more feasible for elderly patients. In fact, our study showed no significant differences in EGFR-TKI-related AEs and dose reduction or treatment discontinuation of osimertinib between the EG and non-EG. However, the frequency of hematotoxicities associated with osimertinib treatment, which did not lead to dose reduction or treatment discontinuation, was significantly greater than the frequency associated with initial EGFR-TKI treatment. An inter-comparison analysis of EG patients revealed that the maximum grade of EGFR-TKI-related AEs associated with osimertinib was significantly lower than that associated with initial EGFR-TKI treatment. Furthermore, regarding the efficacy of osimertinib, no significant differences were observed between the EG and non-EG.

This study has several limitations. First, it was a retrospective study with a small sample size. Second, AEs associated with osimertinib can include bias when compared to prior EGFR-TKIs because patients treated with osimertinib might be accustomed to the management of EGFR-TKI-induced AEs following prior EGFR-TKI treatment. Further investigation regarding the efficacy and safety of osimertinib in elderly patients might be necessary.

In conclusion, this study presented the safety and efficacy 
data regarding the use of osimertinib in elderly patients in comparison to younger patients and initial TKIs. Osimertinib is a feasible treatment for elderly patients with advanced $E G F R$-mutant NSCLC, in the context of both the efficacy and safety of EGFR-TKIs.

\section{Conflicts of Interest}

Dr. Hida received research grants from Ono Pharmaceutical, Novartis Pharma, Chugai Pharmaceutical, Eli Lilly, Taiho Pharmaceutical, AstraZeneca, Nippon Boehringer Ingelheim, Pfizer, Bristol-Meyers Squibb, Clovis Oncology, Eisai, Takeda Bio, Dainippon Sumitomo Pharma, Abbvie, MSD, Merck Serono, Kyowa Hakko Kirin, Daiichi Sankyo, Servier, Kissei, Ignyta, and Astellas. He also received personal fees from Ono Pharmaceutical, Novartis Pharma, Chugai Pharmaceutical, Eli Lilly, Taiho Pharmaceutical, AstraZeneca, Nippon Boehringer Ingelheim, Pfizer, MSD, Kissei, Clovis Oncology, and Bristol-Meyers Squibb. The other Authors have no conflicts of interest to declare.

\section{References}

1 Mok TS, Wu YL, Thongprasert S, Yang CH, Chu DT, Saijo N, Sunpaweravong P, Han B, Margono B, Ichinose Y, Nishiwaki Y, Ohe Y, Yang JJ, Chewaskulyong B, Jiang H, Duffield EL, Watkins CL, Armour AA and Fukuoka M: Gefitinib or carboplatin-paclitaxel in pulmonary adenocarcinoma. N Engl J Med 361: 947-957, 2009.

2 Maemondo M, Inoue A, Kobayashi K, Sugawara S, Oizumi S, Isobe H, Gemma A, Harada M, Yoshizawa H, Kinoshita I, Fujita Y, Okinaga S, Hirano H, Yoshimori K, Harada T, Ogura T, Ando M, Miyazawa H, Tanaka T, Saijo Y, Hagiwara K, Morita S and Nukiwa T: Gefitinib or chemotherapy for non-small-cell lung cancer with mutated EGFR. N Engl J Med 362: 2380-2388, 2010.

3 Rosell R, Carcereny E, Gervais R, Vergnenegre A, Massuti B, Felip E, Palmero R, Garcia-Gomez R, Pallares C, Sanchez JM, Porta R, Cobo M, Garrido P, Longo F, Moran T, Insa A, De Marinis F, Corre R, Bover I, Illiano A, Dansin E, de Castro J, Milella M, Reguart N, Altavilla G, Jimenez U, Provencio M, Moreno MA, Terrasa J, Muñoz-Langa J, Valdivia J, Isla D, Domine M, Molinier O, Mazieres J, Baize N, Garcia-Campelo R, Robinet G, Rodriguez-Abreu D, Lopez-Vivanco G, Gebbia V, Ferrera-Delgado L, Bombaron P, Bernabe R, Bearz A, Artal A, Cortesi E, Rolfo C, Sanchez-Ronco M, Drozdowskyj A, Queralt C, de Aguirre I, Ramirez JL, Sanchez JJ, Molina MA, Taron M and Paz-Ares L: Erlotinib versus standard chemotherapy as firstline treatment for European patients with advanced EGFR mutation-positive non-small-cell lung cancer (EURTAC): a multicentre, open-label, randomised phase 3 trial. Lancet Oncol 13: 239-246, 2012.

4 Yun CH, Mengwasser KE, Toms AV, Woo MS, Greulich H, Wong KK, Meyerson M and Eck MJ: The T790M mutation in EGFR kinase causes drug resistance by increasing the affinity for ATP. Proc Natl Acad Sci USA 105: 2070-2075, 2008.

5 Oxnard GR, Arcila ME, Sima CS, Riely GJ, Chmielecki J, Kris MG, Pao W, Ladanyi M and Miller VA: Acquired resistance to EGFR tyrosine kinase inhibitors in EGFR-mutant lung cancer: distinct natural history of patients with tumors harboring the T790M mutation. Clin Cancer Res 17: 1616-1622, 2011.
6 Janne PA, Yang JC, Kim DW, Planchard D, Ohe Y, Ramalingam SS, Ahn MJ, Kim SW, Su WC, Horn L, Haggstrom D, Felip E, Kim JH, Frewer P, Cantarini M, Brown KH, Dickinson PA, Ghiorghiu S and Ranson M: AZD9291 in EGFR inhibitorresistant non-small-cell lung cancer. N Engl J Med 372: 16891699, 2015.

7 Cross DA, Ashton SE, Ghiorghiu S, Eberlein C, Nebhan CA, Spitzler PJ, Orme JP, Finlay MR, Ward RA, Mellor MJ, Hughes G, Rahi A, Jacobs VN, Red Brewer M, Ichihara E, Sun J, Jin H, Ballard P, Al-Kadhimi K, Rowlinson R, Klinowska T, Richmond GH, Cantarini M, Kim DW, Ranson MR and Pao W: AZD9291, an irreversible EGFR TKI, overcomes T790M-mediated resistance to EGFR inhibitors in lung cancer. Cancer Discov 4: 1046-1061, 2014.

8 Mok TS, Wu YL, Ahn MJ, Garassino MC, Kim HR, Ramalingam SS, Shepherd FA, He Y, Akamatsu H, Theelen WS, Lee CK, Sebastian M, Templeton A, Mann H, Marotti M, Ghiorghiu S and Papadimitrakopoulou VA: Osimertinib or Platinum-Pemetrexed in EGFR T790M-Positive Lung Cancer. N Engl J Med 376: 629-640, 2017.

9 Soria JC, Ohe Y, Vansteenkiste J, Reungwetwattana T, Chewaskulyong B, Lee KH, Dechaphunkul A, Imamura F, Nogami N, Kurata T, Okamoto I, Zhou C, Cho BC, Cheng Y, Cho EK, Voon PJ, Planchard D, Su WC, Gray JE, Lee SM, Hodge R, Marotti M, Rukazenkov Y and Ramalingam SS: Osimertinib in Untreated EGFR-Mutated Advanced Non-SmallCell Lung Cancer. N Engl J Med 378: 113-125, 2018.

10 Barta JA, Zinner RG and Unger M: Lung Cancer in the Older Patient. Clin Geriatr Med 33: 563-577, 2017.

11 Torre LA, Siegel RL, Ward EM and Jemal A: Global Cancer Incidence and Mortality Rates and Trends - An Update. Cancer Epidemiol Biomarkers Prev 25: 16-27, 2016.

12 Maemondo M, Minegishi Y, Inoue A, Kobayashi K, Harada M, Okinaga S, Morikawa N, Oizumi S, Tanaka T, Isobe H, Kudoh S, Hagiwara K, Nukiwa T and Gemma A: First-line gefitinib in patients aged 75 or older with advanced non-small cell lung cancer harboring epidermal growth factor receptor mutations: NEJ 003 study. J Thorac Oncol 7: 1417-1422, 2012.

13 Inoue Y, Inui N, Asada K, Karayama M, Matsuda H, Yokomura K, Koshimizu N, Imokawa S, Yamada T, Shirai T, Kasamatsu N and Suda T: Phase II study of erlotinib in elderly patients with non-small cell lung cancer harboring epidermal growth factor receptor mutations. Cancer Chemother Pharmacol 76: 155-161, 2015.

14 Yoshida T, Kuroda H, Oya Y, Shimizu J, Horio Y, Sakao Y, Hida $\mathrm{T}$ and Yatabe Y: Clinical outcomes of platinum-based chemotherapy according to T790M mutation status in EGFRpositive non-small cell lung cancer patients after initial EGFRTKI failure. Lung Cancer 109: 89-91, 2017.

15 Oya Y, Yoshida T, Kuroda H, Shimizu J, Horio Y, Sakao Y, Inaba Y, Hida T and Yatabe Y: Association between EGFR T790M status and progression patterns during initial EGFR-TKI treatment in patients harboring EGFR mutation. Clin Lung Cancer 18: 698-705 e692, 2017.

16 Eisenhauer EA, Therasse P, Bogaerts J, Schwartz LH, Sargent D, Ford R, Dancey J, Arbuck S, Gwyther S, Mooney M, Rubinstein L, Shankar L, Dodd L, Kaplan R, Lacombe D and Verweij J: New response evaluation criteria in solid tumours: revised RECIST guideline (version 1.1). Eur J Cancer 45: 228247, 2009. 
17 Inoue A, Kobayashi K, Usui K, Maemondo M, Okinaga S, Mikami I, Ando M, Yamazaki K, Saijo Y, Gemma A, Miyazawa H, Tanaka T, Ikebuchi K, Nukiwa T, Morita S and Hagiwara K: First-line gefitinib for patients with advanced non-small-cell lung cancer harboring epidermal growth factor receptor mutations without indication for chemotherapy. J Clin Oncol 27: 1394-1400, 2009.

18 Morikawa N, Minegishi Y, Inoue A, Maemondo M, Kobayashi K, Sugawara S, Harada M, Hagiwara K, Okinaga S, Oizumi S, Nukiwa T and Gemma A: First-line gefitinib for elderly patients with advanced NSCLC harboring EGFR mutations. A combined analysis of North-East Japan Study Group studies. Expert Opin Pharmacother 16: 465-472, 2015.
19 Rossi S, D'Argento E, Schinzari G, Dadduzio V, Di Noia V, Cassano A and Barone C: Are TKIs favourable for the elderly with non-small-cell lung cancer? Oncotarget 7: 46871-46877, 2016.

20 Tanaka H, Taima K, Tanaka Y, Itoga M, Ishioka Y, Nakagawa H, Baba K, Hasegawa Y, Takanashi S and Tasaka S: A phase I study of afatinib for patients aged 75 or older with advanced non-small cell lung cancer harboring EGFR mutations. Med Oncol 35: 34, 2018.

Received July 25, 2018

Revised August 16, 2018

Accepted August 20, 2018 